\title{
ASSERTION, JUSTIFICATORY COMMITMENT, AND TRUST
}

\author{
FERnANDo Rudy HilleR \\ Universidad de Stanford \\ ferudy@stanford.edu
}

\begin{abstract}
This paper discusses the commitment account of assertion (CAA), according to which two necessary conditions for asserting that $p$ are the speaker's undertaking a commitment to justify her assertion in the face of challenges and the speaker's licensing the audience to defer justificatory challenges back to her. Relying on what I call the "cancellation test," and focusing on Robert Brandom's version of the CAA, I show that the latter is wrong: it is perfectly possible to assert that $p$ even while explicitly disavowing the justificatory commitment and while refusing to issue a deferring license. Then I sketch an alternative to the CAA, the trust account of assertion, according to which speakers necessarily present themselves as trustworthy concerning $p$ 's truth whenever they assert $p$. I explain why this is different from undertaking a justificatory commitment, and offer some reasons for thinking that this is a more promising account.
\end{abstract}

KEY WORDS: Asserting; Justification; Brandom; Inferentialism; Trustworthiness.

\section{Resumen}

De acuerdo con la explicación de la aserción defendida, entre otros, por Robert Brandom, un par de condiciones necesarias para que un acto de habla cuente como tal son, primero, que el hablante adquiera el compromiso de justificar su aserción si es requerido para hacerlo y, segundo, que el hablante extiende a su audiencia una licencia para que esta delegue en el primero la responsabilidad de ofrecer una justificación. En este artículo muestro, con base en lo que llamo la "prueba de la cancelación", que esta explicación es incorrecta, dado que es perfectamente posible para un hablante afirmar $p$ al tiempo que rechaza el compromiso de justificar su aserción y se niega a extender dicha licencia. Después ofrezco el bosquejo de una explicación alternativa, de acuerdo con la cual un hablante, al afirmar $p$, necesariamente se presenta a sí mismo como confiable respecto a la verdad de $p$. Finalmente ofrezco razones para preferir esta explicación a la de Brandom.

PALABRAS CLAVE: Aserción; Justificación; Brandom; Inferencialismo; Confianza.

Should the speech act of assertion be understood as the undertaking of a commitment to justify the proposition asserted? Some philosophers, most notably Brandom (1983; 1994; 2010), but also Kölbel (2011), Watson (2004), and MacFarlane (2005; 2011) have thought that it should. However, Pagin (2004) has argued that undertaking a 
justificatory commitment is not sufficient for making an assertion, since an explicit undertaking of a commitment to justify $p$ does not amount to asserting $p$. My negative goal in this paper, and the one that occupies the bulk of it, is to show that such commitment is not necessary either. Brandom's account will be the target of my arguments, but they can easily be applied to other versions of the commitment account as well, although I do not do so here. My positive goal is to sketch a replacement for the commitment account, what I call the trust account. The central idea of the latter is that by asserting that $p$ the speaker is presenting herself as trustworthy regarding $p$ 's truth, which is different from undertaking a justificatory commitment to vindicate $p$ 's truth if challenged. ${ }^{1}$

The paper has five sections: in section 1 I present what I take to be the least common denominator among different accounts of assertion, and explain the additions proposed by Brandom's commitment account. In section 2 I offer my argument against these additions, showing that they should not be included among the necessary conditions of assertion. In section 3 I address two important objections on Brandom's behalf. In section 4 I sketch the trust account and finally in section 5 I restate the main findings of the paper.

\section{The philosophical commonsense view of assertion and the commitment account}

In this section I will present what I take to be the least common denominator among different accounts of assertion, what I will call (oxymoronically) "the philosophical commonsense view of assertion". My purpose in doing so is to prepare the ground for the discussion in the second section of the paper and to show how the commitment account can be seen as building its requirements on top of this "commonsense" conception.

When a speaker $\mathrm{S}$ asserts that $p$, what is she doing? First, she is expressing a proposition. ${ }^{2}$ Second, she is expressing it with a certain force. Explaining what exactly this "force" consists in is as difficult as explaining what assertion is, but as a first pass we can say that it amounts to a "judgmental force" (Pagin 2004, p. 836 n. 10). Again, the notion of

\footnotetext{
${ }^{1}$ Moreover, as I will argue in section 4, one can present oneself as trustworthy in asserting $p$ while explicitly refusing to undertake a justificatory commitment for one's assertion.

${ }^{2}$ My discussion here is limited to literal assertions, that is, assertions in which the speaker asserts $p$ by expressing the proposition that $p$.
} 
"judgmental force" is not crystal clear, but at least points us in the right direction: when $\mathrm{S}$ makes an assertion that $p$, the proposition $p$ is not only expressed but judged to be the case. In other words, when $\mathrm{S}$ makes an assertion that $p$ she is presenting $p$ as being the case or as being true. So we can say that

$(\mathrm{CS} 1)^{3}$ To assert that $p$ is to present the proposition $p$ as true. ${ }^{4}$

Of course, (CS1) is not intended as an informative analysis, since the key notion of "presenting as true" is as obscure as that of "judgmental force." Moreover, some philosophers think that the very notion of truth should be understood in terms of assertion, not the other way around (Dummett 1959). Still, (CS1) is not completely uninformative, since it is a promising first stab in the task of individuating the speech act we are concerned with. (CS1) is then the first element in the philosophical commonsense view of assertion. I call it thus because I take it that the four main accounts of assertion are committed, at least implicitly, to it: these are the expressive, effect, normative, and commitment accounts. ${ }^{5}$ My concern in this paper is restricted to the last one, but I think is clear that (CS1) is a component of all of them. ${ }^{6}$

Now, we may note that there are several speech acts that can be

3 "CS" stands for "commonsense."

${ }^{4}$ Pagin (2004, p. 837) presents this analysis just as an example without endorsing it. Watson (2004, p. 58) advances a similar analysis, but he does endorse it: "A core idea of assertion is the idea of putting something forward as true."

${ }^{5}$ For a discussion of these four accounts see MacFarlane (2011).

6 The expressive account is represented by Bach and Harnish (1979), for whom asserting is expressing a belief. Since belief is a propositional attitude in which a proposition is taken to be true, in expressing the belief that $p$ one is presenting $p$ as true. The effect account is represented by Stalnaker (1978; 2002), who understands assertion in terms of its "essential effect," i.e., adding the proposition asserted to the "context set" or the "common ground" of the conversation. Since the main purpose of a serious conversation is to transmit information, whatever gets incorporated to the common ground is taken to be true. The normative account is represented prominently by Williamson (2000); according to him, assertion is understood as the unique speech act governed by a certain norm - the norm of assertion. Williamson proposes the knowledge norm ("assert $p$ only if one knows $p$ ") and, since knowledge is factive, he is clearly committed to (CS1). Finally, the commitment account, represented prominently by Brandom $(1983 ; 1994 ; 2010)$, conceives assertion both as the undertaking of a commitment to justify $p$ if suitable challenged and as the "issuing [of] an inference license" (1983, p. 639). As will be discussed in the text, both the commitment and the inference license presuppose that $p$ is true. In section 2 below I explain in more detail why (CS1) is a component of the commitment account. 
characterized as presenting a proposition as true: guessings and assertions are cases in point. ${ }^{7}$ However, precisely because of this, assertions cannot be characterized simply as presenting a proposition as true, since that would fail to distinguish between assertions and guessings. So what is involved in assertions, beside the mere presentation of $p$ as true?

The idea of "judgmental force" mentioned above provides, again, an important clue: judging that $p$ is different from guessing that $p$, even though in both cases $\mathrm{p}$ is presented as true. In judging, but not in guessing, one takes oneself to have adequate or sufficient grounds for thinking that the proposition judged as true is indeed true. And so, if asserting were the speech act by which a proposition is presented as true with judgmental force, in asserting that $p$ the speaker would not only be presenting $p$ as true but, at the same time, would be presenting herself as having adequate or sufficient grounds for taking $p$ as true. Hence, if this is correct, we can supplement the philosophical commonsense view of assertion as follows:

(CS2) To assert that $p$ is to present the proposition $p$ as true by presenting oneself as having adequate or sufficient grounds for taking $p$ as true.

Again, (CS2) is not intended as an informative analysis, since it does not explain in what this "presenting oneself as having adequate or sufficient grounds" consists in. Still, (CS2) is useful because it provides an important clue for individuating the speech act of assertion: in asserting that $p$, unlike what happens with other speech acts in which the speaker puts forward $p$ as true (conjecturing, hypothesizing, guessing, betting, supposing, etc.), the speaker presents herself as having adequate or sufficient grounds for taking $p$ as true.

It may seem strange that I include (CS2) as part of what I have called the philosophical commonsense view of assertion, since it may be thought that (CS2) would not be endorsed by all four approaches mentioned above. Actually, however, I think that all of them are committed to something like (CS2). First, the normative account is the one that most obviously embraces (CS2): the knowledge norm of assertion, proposed by Williamson, can be seen as a normative rendering of (CS2), which only describes what the speaker is doing in asserting that $p$. Other variants of the normative account - such as the one

7 And also bettings, suppositions, pretenses, conjectures, etc. 
proposed by Lackey (2008) with her "reasonable to believe" norm- are also attempts to capture (CS2). Second, the effect account claims that asserting that $p$ amounts to proposing to add $p$ to the conversational common ground, but since the interest of the parties in a serious conversation is the exchange of information, they are interested in adding only true propositions to the common ground. They all know this, and so it is natural to think that when one of them proposes to add $p$ to the conversational common ground she is presenting herself - and taken by others as presenting herself- as having adequate grounds for taking $p$ as true. Third, the expressive account may appear not to embrace (CS2), since according to it assertion is the expression of belief, which is an attitude one can adopt without having adequate grounds. However, if, as some philosophers maintain, doxastic deliberation aims at knowledge (Hinchman 2013), then one can say that asserting is the expression of knowledge, not of belief (conjecturing may be the speech act that expresses belief). ${ }^{8}$ A piece of evidence that in asserting that $p$ one is usually presenting oneself as expressing knowledge, not belief, is that a speaker who thinks that her assertion lacks adequate grounds would normally hedge it thus: " $p$, I believe."

Finally, the commitment account - the one I am interested in here - attempts to capture (CS2) by introducing the idea that asserting that $p$ involves being committed to the truth of $p$. The main task faced by the proponent of this account is, of course, to explain what is involved in this commitment. According to Brandom's version of the account, which will be the target of my arguments, the commitment involves both an aspect of authority and an aspect of responsibility: "in asserting that $p$ one is doing two things. On the side of authority, one is licensing others to reassert one's claim. On the side of responsibility, one is committing oneself to justify the claim if suitably challenged" (2010, p. 26-7). Supplementing this passage with elements from his 1983 article, we can say that, for Brandom, a commitment to the truth of $\mathrm{p}$ can be broken down in these two dimensions:

Authority dimension (AD)

(AD1): Issuing an inference license authorizing further assertions (1983, p. 639).

(AD2): Issuing a deferring license authorizing the audience to

${ }^{8}$ According to Williamson (2000), knowledge is a mental attitude or a "state of mind"; if this is so, then knowledge can be endorsed by the expressive account as the attitude expressed in assertion. 
defer to the speaker the justificatory responsibility for the assertion (1983, p. 642). ${ }^{9}$

Responsibility dimension $(R D)$ : "The commitment involved in asserting [is] the undertaking of justificatory responsibility for what is claimed" (1983, p. 641).

The thesis I will defend in the next section is this: against Brandom, the illocutionary force of assertion can be analyzed neither as the issuing of a deferring license (AD2) nor as the commitment to justify $p$ if challenged (RD). Hence, the issuing of a deferring license and the commitment to justify $p$ if challenged are not necessary elements of assertion. However, as I will explain below, I agree with Brandom that a necessary component of assertoric force is the issuing of an inference license (AD1). ${ }^{10}$ In light of what I have said in this section, the argument of the next one can be read as follows: Brandom's attempt to capture (CS2) by way of (AD2) and (RD) fails, since — as my "cancellation test" will show- (CS2) is indeed a necessary condition of assertion, while $(\mathrm{AD} 2)$ and (RD) are not.

\section{The argument against the commitment account}

In this section I present my argument against Brandom's version of the commitment account of assertion (CAA). The argument runs as follows:

(i) If the CAA is true, then it is not possible to make assertions

${ }^{9}$ Notice that although $\mathrm{AD} 2$ and $\mathrm{RD}$ below are concerned with justificatory responsibility, they are distinct conditions: AD2 is concerned with the speaker's authorizing the audience to defer to him the justificatory responsibility, while RD is concerned with the speaker actually undertaking such responsibility. Normally, of course, once a speaker has issued a deferring license she will thereby have undertaken justificatory responsibility. Still, as we will see in the next section, we need different arguments to attack $\mathrm{AD} 2$ and $\mathrm{RD}$, and this is further evidence that they really are different conditions.

10 I have to add the caveat that my main reason for employing Brandom's notion of an inference license is to use it as the basic ingredient in an ad hominem argument against Brandom, presented in 2.1. and 2.2. below. The argument goes roughly like this: if issuing an inference license is the basic element of assertion, then Brandom is committed to accepting my examples as assertions, since hearers can make inferences based on the content of the speaker's utterances, which amounts to taking those utterances as assertions. 
while disavowing the commitment characteristic of assertion.

(ii) However, it is possible to make assertions while disavowing that commitment (as characterized by Brandom).

(C) Brandom's version of the CAA is false. ${ }^{11}$

The proponent of the CAA is clearly committed to (i) since if, as he claims, what distinguishes the speech act of assertion is the undertaking of a specific commitment, it follows that disavowing that commitment amounts to disavowing one's speech act as an assertion. ${ }^{12}$ The core of my argument is the defense of premise (ii), which I proceed to do in what follows. My strategy will be to identify what kind of disavowals can be made by a speaker while still counting as asserting that $p$ in a certain context. I will accomplish this by means of what I call the "cancellation test" for assertion. This test will, I hope, provide further evidence that the philosophical commonsense view of assertion (CS1 and CS2) outlined above indeed captures necessary conditions of assertion. As a preliminary example of how the test is supposed to work, consider the following sentence:

(1) The cat is on the mat and/but this is false.

Does a speaker uttering (1) count as asserting something? I take it that the answer is no: she is neither asserting that the cat is on the mat, since she immediately claims this is false (or "cancels" the truth of the previous utterance), nor is she asserting that it is false that the cat is on the mat, since she started by claiming the opposite. If this interpretation of (1) is correct, then it lends support to (CS1): a necessary condition of assertion is presenting a proposition as true, and this is why (1) does not succeed in asserting anything. Thus, the cancellation test shows that one cannot assert that $p$ while disavowing (or cancelling) the presentation of $p$ as true.

11 As I said above, I think the argument I present in this section will work equally well against other versions of the CAA, although for reasons of space I limit myself to attack Brandom's.

12 I interpret the proponent of the CAA as providing necessary (and perhaps sufficient) conditions for assertion. However, one of the possible objections to my argument that I consider below (in 3.1.) on Brandom's behalf is, precisely, that the latter's account should not be read as providing necessary and sufficient conditions, but as doing something else, such as providing a paradigm of assertion from which certain assertions ("bare assertions") can diverge. 


\section{1. (AD2) is not a necessary condition of assertion}

Now consider:

(2) Don't quote me, but the cat is on the mat.

Does a speaker uttering (2) count as asserting that the cat is on the mat? The answer is clearly yes, even though she is explicitly disavowing one aspect of the authority that, according to Brandom, is a necessary condition for asserting that $p$, namely, issuing a deferring license (AD2 above):

An assertion in force licenses others to re-assert the original claim (and to assert its immediate consequences) deferring to the author of the original assertion the justificatory responsibility which would otherwise thereby be undertaken (1983, p. 642, italics in the original).

It seems clear that the speaker in (2), by introducing her assertion with the words "Don't quote me", is disavowing precisely the kind of deferring Brandom claims in this passage to be characteristic of asserting. In effect, the natural reading of the disavowal that accompanies the assertion in (2) is that the speaker is not authorizing the audience to defer to her the responsibility of justifying the proposition asserted.

Perhaps Brandom would object that (2) is a hedged assertion, on a par with, say, "I'm not sure, but I think (believe) that the cat is on the mat". ${ }^{13}$ However, I think it is pretty clear that (2) is not a hedged assertion; it is, rather, a full-blown assertion accompanied by a disavowal to the effect that the author of the assertion wants to remain, so to speak, anonymous. A clue that (2) is a full-blown assertion is that a speaker uttering (2) is "issuing an inference license" (Brandom 1983, p. 639; see AD1 above) or is "adding $p$ to the [conversational] score" (Kölbel 2011, p. 65). I think both of these ways of characterizing the essential effect ${ }^{14}$ of assertion are roughly correct, since they capture (at least part of) what is meant by the phrase "presenting $p$ as true" or (CS1). A proof that this is so is that the following utterances would not count as assertions:

(3a) The cat is on the mat, and/but you can't infer anything from it, not even that the cat is on the mat.

${ }^{13}$ See Brandom (1994, p. 228).

14 Stalnaker (1978). 
(3b) The cat is on the mat, and/but you can't add the proposition that the cat is on the mat to the conversational score.

It is clear that (3a) and (3b) are like (1), in that the second part of the utterance (after the "and/but") defeats or cancels what appears to be an assertion in the first part. (3a) is clearer, since prohibiting to infer a proposition from itself is equivalent to denying it, i.e., to present it as false. $(3 b)$ is perhaps less clear, since it incorporates the term of art "conversational score", but in a basic understanding of it as what can be presupposed in further moves in a conversation it is clear that the second part of (3b) is equivalent, once again, to presenting the proposition in question as false, since false propositions are not part of the conversational score.

So Brandom's notion of issuing an inference license (AD1), understood as a "warrant for further assertions" (1983, p. 639), can be said to adequately capture a necessary condition of assertion, namely, (CS1). ${ }^{15}$ Notice that the issuing of a warrant or license for further inferences does not depend on the speaker's intentions, but rather is part of what it is to assert a proposition. A hint that this is so is that utterances that cancel the inference license — such as (3a) - do not count as assertions. So (AD1) can be seen as a necessary condition of assertion. However, Brandom also includes in the authority dimension the deferring of justificatory responsibility to the speaker, that is, condition (AD2), which as (2) illustrates is not a necessary component of assertion, since it can be cancelled without destroying the peculiar illocutionary force of assertion. In conclusion, the authority dimension of Brandom's analysis is acceptable if it gets restricted to the issuing of an inference license, but it is not if we include the issuing of a deferring license.

\section{2. (RD) is not a necessary condition of assertion}

Let us turn now to the responsibility dimension (RD) of Brandom's analysis. We saw above that Brandom understands the commitment a speaker incurs in asserting that $\mathrm{p}$ as the undertaking of justificatory responsibility or, more, precisely, the undertaking of "the conditional taskresponsibility to justify the claim if challenged" (1983, p. 642). ${ }^{16}$ Brandom

${ }^{15}$ But see a caveat to this claim in footnote 10 above.

${ }^{16}$ By "task-responsibility" Brandom means a kind of responsibility "requiring the performance of a task of some kind for its fulfillment" (1983, p. 641). In subsection 3.2. below I discuss the sense in which the task-responsibility characteristic of assertion is, according to Brandom, conditional. 
makes it clear that so undertaking is not a spin-off of asserting, but rather an essential component of what it is to make an assertion. When one asserts that $p$ one is presenting $p$ as true by presenting oneself as having adequate grounds for taking $p$ as true, a feature of assertion Brandom cashes out in terms of warranting or licensing further assertions by presenting oneself as entitled to the original assertion. But, he says, "Failure to defend one's entitlement to an assertion voids its social significance as inferential warrant for further assertions ... Endorsement is empty unless the commitment can be defended" (1983, p. 641). ${ }^{17}$ Hence, for an assertion that $p$ to be able to warrant further assertions the assertor must, in Brandom's view, undertake the commitment to defend $p$ if challenged. It follows that if the speaker dodges this commitment and refuses to justify her assertion that $p$, then this assertion would not warrant further assertions, which in turn means that it is not an assertion after all (see (3a) above).

My claim will be that the commitment to justify an assertion is not a necessary condition for making one, since a speaker can make an assertion (and be taken by others as making one) while refusing to justify it. The example supporting this claim goes as follows: suppose that Albert and Bernard are discussing the bad economic shape of the company they both work for, and at some point Albert says:

(4) There is a downsizing coming in a couple of weeks.

Obviously, Bernard gets alarmed and asks: "How do you know?" Albert responds as follows:

(4a) Sorry, I won't say more, but there is a downsizing coming in a couple of weeks.

Are (4) and (4a) assertions that there is downsizing coming in a couple of weeks at Albert's and Bernard's company? I think the answer is clearly yes, despite the fact that in uttering (4) Albert is not undertaking justificatory responsibility for his claim, as he makes clear when he

17 Watson (2004, pp. 69-70) shares this opinion: "My commitment to $p$ 's being defensible does seem to oblige me to engage in justificatory activity... The primary commitment can remain fully in place without the expectation of triggering further discursive responsibilities, but it could not serve its discursive/epistemic functions if it were systematically and generally divorced from justificatory commitments. The primary commitment to $p$ 's being defensible would become empty" (italics added). 
reasserts the claim in (4a). But if (4) and (4a) are assertions, even though the speaker is explicitly (in 4a) disavowing justificatory responsibility for his utterances, then this means that Brandom is wrong in supposing that undertaking such responsibility is essential for making assertions.

A natural question at this point is, again, how I can tell that (4) and (4a) are full-blown assertions and not hedged assertions or other kind of speech act altogether. As in the case of (2), I appeal here to Brandom's own conception of asserting as the issuing of an inference license. So we can rephrase the question like this: Has Albert issued a license to Bernard to make inferences based on the propositions expressed by utterances (4) and (4a)? For Brandom this question is settled not by appealing to the speaker's intentions, but rather by appealing to the kind of updates to the "normative score" that a scorekeeper attributes to the speaker's performance:

A scorekeeper who acknowledges the authority of one's assertion will count those in the audience as having inherited from it prima facie entitlement ... to the content one has endorsed (Brandom 2010, p. 27).

So if Bernard acknowledges Albert's authority in uttering (4) and (4a)— if, in other words, he takes himself to have inherited from Albert's utterance a prima facie entitlement to the proposition that there is a downsizing coming in a couple of weeks - then, by Brandom's own lights, Albert has asserted this proposition by uttering (4) and (4a).

Of course, Brandom would protest at this point by saying that Bernard cannot acknowledge Albert's authority once the latter has made it clear with (4a) that he is disavowing justificatory responsibility. How should we decide the disagreement between Brandom and me? Are we just confronted with a clash of intuitions? I do not think so; I think it is perfectly possible (even by Brandom's own lights) for Bernard to acknowledge Albert's authority in the sense of the passage just quoted, that is, as taking the audience of Albert's claim (namely, himself) to have inherited a prima facie entitlement to the proposition expressed by it. How can Bernard do that in spite of Albert's refusal to justify his claim? The answer is simple: by proceeding to make inferences based on the content of Albert's utterance. For example, suppose that in the company there are two departments-Finance and Planning, say — and Bernard works in the second. He knows that the last downsizing took place in Finance, and that it is customary in the company to alternate the firings between the two departments. Armed with this background knowledge, Bernard can infer the following from Albert's utterance: 
(5) There will be a downsizing in Planning in a couple of weeks.

If he does infer (5), this will mean that he has acknowledged Albert's authority in uttering (4) and (4a). In other words, he would have taken Albert as asserting that there is a downsizing coming in a couple of weeks —despite Albert's explicit disavowal of the conditional task-responsibility to justify his claim.

Now Brandom could insist that Bernard is not warranted in inferring (5) on the basis of (4), since in (4a) Albert disavowed the responsibility to justify his claim. But it is easy to see that Bernard can be warranted in acknowledging Albert's authority in uttering (4) despite Albert's disavowal of responsibility in (4a). For suppose that Bernard has evidence that Albert usually is well-informed when it comes to the subject of the company's affairs; if this is the case, then Bernard can take Albert's assertion at face value despite the latter's refusal to undertake the responsibility to justify his claim. ${ }^{18}$

Another possible objection to my argument goes as follows: Brandom could say that undertaking such responsibility does not depend on the speaker's intentions, but rather on the social significance of her performance. In other words, just as a speaker issues an inference license every time she asserts something, regardless of whether she wants to issue such a license or not (as I admitted in section 2.1. above), a speaker undertakes justificatory responsibility each time she asserts something, regardless of her intentions - and regardless of disavowals such as the one in (4a). ${ }^{19}$

My answer is this: as we saw above, Bernard can take Albert as making an assertion, since the former could use the latter's utterance of

18 My claim is not that such evidence is necessary for Bernard if he is to accept Albert's assertion in spite of the latter's disavowal of responsibility. I introduced this variant just to emphasize that the speaker's commitment to justify his claim is not necessary for her audience to take her utterance as an assertion, since the audience could have alternative grounds for thinking that the speaker knows what she is talking about. But, again, such alternative grounds are not necessary: I think that the mere fact that Albert uttered (4), and despite (4a), is enough for Bernard's taking the utterance as an assertion. (I defend the claim that this kind of evidence is not necessary for taking an utterance as an assertion in section 4 below.) The only clear restriction in doing so is that Bernard should not have conclusive reason to think that Albert does not (or could not) know what he is talking about. On this last point, see footnotes 22 and 32 below.

19 Or perhaps the objector could say that introducing such disavowals along with a putative assertion simply destroys the assertoric force of the utterance. But I have blocked this line of attack by showing that Bernard could infer (5) from (4), therefore acknowledging Albert's authority to assert that there is a downsizing coming in a couple of weeks. 
(4) as the basis for inferring (5), in spite of Albert's disavowal of justificatory responsibility in (4a). So this shows, once again, that Albert's disavowal does not disqualifies him as an assertor, and this fact is acknowledged by Bernard when he proceeds to make an inference based on (4) in spite of (4a). Thus, Brandom's possible rebuttal that the justificatory responsibility persists in spite of the speaker's intentions to the contrary does not hold: notice that the scorekeeper (Bernard in this case) can acknowledge at the same time that Albert has issued an inference license (i.e., that he has asserted something) and that he will not undertake the task of providing a justification even after being challenged (i.e., that he has dodged the justificatory responsibility). So my main contention still stands: undertaking justificatory responsibility is not necessary for making (and for be taken as making) assertions. ${ }^{20}$

This is a good moment to discuss one possible ambiguity in Brandom's phrase "undertaking justificatory responsibility". If one takes the phrase to mean something like "presenting a proposition as justified" or "presenting oneself as having adequate justification" I would agree that asserting that $p$ involves something like this, irrespective of the speaker's intentions. This amounts to (CS2), the second element in the philosophical commonsense view of assertion. To see why (CS2) is a necessary element of assertion, let us use my proposed cancellation test again. Consider the following sentences:

(6) The cat is on the mat, and/but there is absolutely no way of justifying this claim.

and

(7) The cat is on the mat, and/but I have absolutely no justification for this claim.

Do (6) and (7) count as assertions? I think the answer is no: in these cases, the disavowal that follows the putative assertion blocks it from entering into inferential relations. ${ }^{21}$ The audiences of (6) and (7) would not be warranted in inferring from these utterances something like "The mat is below the cat", which clearly follows from "The cat is on the mat".

${ }^{20}$ I return in 3.2. below to a different variant of this objection, one that puts emphasis on the idea that the justificatory responsibility undertaken by the speaker is just conditional.

${ }^{21}$ By the "putative assertion" I mean, of course, "the cat is on the mat." An audience 
Why is that? The reason, I suggest, is that a necessary condition for asserting -one that differentiates it from other speech acts such as guessing - is the presentation of a proposition as true by way of the speaker's presenting herself as having adequate or sufficient grounds for taking it as true (condition (CS2)). If this were indeed a necessary condition of assertion, that would explain why (6) and (7) cannot count as asserting the proposition "The cat is on the mat": one cannot have adequate or sufficient grounds for taking a proposition as true if no justification is possible (as in (6)) or if one lacks justification (as in (7)). ${ }^{22}$

Notice, however, that (CS2) is not equivalent to "undertaking justificatory responsibility" as Brandom understands the phrase (this is the ambiguity I mentioned above). For, as Brandom understands the phrase, it means more than just presenting oneself as having adequate grounds for the proposition in question; it means actually committing oneself to justify the proposition if (appropriately) ${ }^{23}$ challenged. Brandom claims that "Endorsement [of a proposition] is empty unless the commitment [to vindicate one's claim] can be defended" (1983, p. 641), by which he means that one cannot issue an inference license through one's utterance unless one is committed to defend one's claim in the face of challenges. But, as I have shown with my examples (4) and (4a), such commitment is not a necessary condition for licensing inferences through one's utterances - that is, for asserting. So Brandom is wrong in thinking that the endorsement characteristic of assertion is empty unless the commitment to justify is actually present.

\section{Two further objections on Brandom's behalf}

\subsection{Bare assertions}

I want to consider now what I take to be the two more important objections to the argument presented in the previous section (I consider one in this subsection and the other in 3.2.). In his 1983 article Brandom

can employ (6) or (7) to make further inferences, such as "The speaker doesn't know what he's talking about", but that's not an inference based on the proposition "The cat is on the mat", which is the object of my concern here.

22 So I think Austin was right when he suggested that one cannot assert (or state) something for which one could not have evidence for: "You cannot now state how many people there are in the next room; if you say 'There are fifty people in the next room', I can only regard you as guessing or conjecturing" (1975, p. 138).

23 I discuss the relevance of this caveat in 3.2 . below. 
admits that there are cases in which an utterance counts as an assertion despite the speaker's "failure to shoulder the usual justificatory burden" (p. 643). He considers two such kinds of cases: first, cases in which "it is inappropriate to issue a justificatory challenge", as when the Pope is speaking ex cathedra or a speaker is reporting her mental states. Second, cases in which "a speaker may cheerfully admit that no justification is possible for his claim, and yet insist on asserting it" (idem). Brandom calls these kinds of cases "bare assertions" and claims that "there is reason to treat these cases as derivative from or parasitic on a paradigm in which justificatory responsibility is undertaken as a matter of course" (idem). So perhaps Brandom would concede that my examples (2) and (4a) are indeed assertions - even though in them the speaker refuses, respectively, to issue a deferring license and to "shoulder the usual justificatory burden"- but he would qualify his concession by noting that they are bare assertions and as such "derivate or parasitic." If this were the case, I would have failed to prove that shouldering the justificatory burden and issuing a deferring license are not necessary conditions of paradigmatic cases of assertion.

I will respond to this objection by focusing on the second kind of cases, ${ }^{24}$ and leave the discussion of the first kind for the next subsection. What I want to argue is that if Brandom is correct in thinking that $\mathrm{AD} 2$ and $\mathrm{RD}$ are necessary conditions of assertion, then the notion of "bare assertion" makes no sense and must be abandoned. But if this is so, then Brandom is faced with a dilemma: either he accepts that (2) and (4a) are assertions simpliciter, which would mean that AD2 and RD are not necessary conditions after all, or he flat out denies that they are assertions at all, which is something he does not seem to be prepared to do, because he introduced the notion of "bare assertion" precisely to accommodate cases like these.

To see why the notion of bare assertion makes no sense if $\mathrm{AD} 2$ and $\mathrm{RD}$ are necessary conditions, think of what would be the parallel case with

${ }^{24}$ I charitably interpret Brandom's characterization of these cases ("a speaker may cheerfully admit that no justification is possible for his claim, and yet insist on asserting it") as akin to my example (4a), not to my examples (6) and (7). I have claimed that the former, in which the speaker refuses to undertake justificatory responsibility for his claim, is a genuine assertion, while the latter, in which the speaker claims that there is no justification for his claim, are not (they are, perhaps, guesses). If, by contrast, Brandom's idea is that cases such as (6) and (7) are in fact assertions, although bare ones, then the argument presented at the end of the previous section suffices to show that this is wrong: they cannot be assertions, not even bare ones, given that they fail to enter into inferential relations. 
promising. Suppose, plausibly enough, that a necessary condition for an utterance to count as the issuing of a promise to $\varphi$ is the speaker's presenting herself as intending to $\varphi$. Let us call this necessary condition the "Intending Condition" (IC) for promising. Notice that the IC does not need to be understood as depending on the speaker's intentions: one can be taken by others as having promised to $\varphi$ regardless of whether one actually intends to $\varphi$. The idea is, rather, that under certain circumstances an utterance of the form "I will $\varphi$ " counts as the issuing of a promise. (Of course, the most obvious way to promise is to say "I promise to $\varphi$ ", which, again, under normal circumstances counts as a promise, regardless of whether the speaker actually intends to $\varphi$.) Now let us apply the cancellation test to see if an utterance that cancels the IC could count as the issuing a promise:

(8) I promise to $\varphi$, but my $\varphi$-ing depends on whether I feel like $\varphi$ ing when the time comes.

I think it is pretty clear that (8) could not be counted as a promise, and there is an easy explanation why not: saying that your $\varphi$-ing is contingent on your future motivational makeup is tantamount to admitting that you do not have now the intention to $\varphi$. So the impossibility of promising by way of an utterance that cancels the IC shows that the latter is indeed a necessary condition for an utterance to count as issuing a promise. Now notice how inadequate would be for someone to reply: "Well, perhaps (8) is a bare promise, a promise derivative from or parasitic on the paradigmatic cases of promising". If IC is, as it seems to be, a necessary condition of promising, then a putative promise that tries to sidestep this condition is simply not a promise at all.

I claim that exactly the same reasoning applies to necessary conditions for asserting: if $\mathrm{AD} 2$ and $\mathrm{RD}$ are, as Brandom suggests, necessary conditions, then he must say that utterances such as (2) and (4a) above, which include explicit disavowals of AD2 and RD respectively, are simply not assertions - not even bare ones. So he must abandon the notion of bare assertion. However, this poses the dilemma mentioned above: either Brandom follows through with his commitments and denies that utterances such as (2) and (4a) are assertions - which flies in the face of the apparent fact that one can make assertions by uttering sentences like these, a fact that presumably led Brandom to incorporate the notion of bare assertion in the first place - or he accepts that (2) and (4a) are assertions simpliciter, which would concede my main point that AD2 and $\mathrm{RD}$ are not, after all, necessary conditions of assertion. 
Perhaps Brandom would protest that his account does not intend to provide necessary and sufficient conditions for assertion, but rather something like inferential norms for attributions of assertion..$^{25}$ On this interpretation, the inferential norms are AD1, AD2 and RD, and the idea is that in paradigmatic cases scorekeepers take speakers to have asserted something when compliance with these norms can be presupposed. Then Brandom can allow for cases of bare assertions, where speakers ignore one or more of these norms, by arguing not that they count as assertions despite disregarding necessary conditions for asserting (which, as I claimed above, would be absurd), but rather that they are parasitic on the paradigmatic cases, which now would mean something like this: sometimes scorekeepers let pass some utterance as an assertion, despite the fact that it flouts one or more inferential norms, whenever they have some relevant conversational purpose that would be served by proceeding in this way; however, they always keep in mind that these cases are exceptional. If this strategy works, the Brandom can accommodate cases like (2) and (4a) by acknowledging that they are indeed assertions, but since they are parasitic in the sense just explained, they fail to show that the norms mentioned above are not essential for assertion.

This strategy does not work, however, because Brandom lacks a non-question-begging argument supporting the idea that his paradigmatic cases are indeed paradigmatic. His argument cannot be, of course, that

${ }^{25}$ I owe this possible rebuttal to Mark Crimmins. Notice, however, that there are passages in Making It Explicit (1994) in which Brandom clearly presents himself as offering sufficient and necessary conditions (see, for example, p. 159). See also the following passage, where he clearly indicates that being subject to a demand for justification is a necessary condition for an utterance being an assertion: "That claims play the dual role of justifier and subject of demand for justification is a necessary condition of their kind properly being called assertional commitments" (p. 168). In this connection, an anonymous referee urged me to discuss the possibility that Brandom's considered position is that $\mathrm{AD} 1, \mathrm{AD} 2$, and $\mathrm{RD}$ are sufficient, but not necessary, conditions for asserting. As a mere exegetical point, I think it's clear that, as the passage just quoted shows, Brandom does seem to conceive these conditions as necessary. Of course, the philosophically interesting question is whether these conditions can be conceived as merely sufficient, independently of Brandom's take on the matter. What I can say here is that I find Peter Pagin's (2004, p. 839-40) argument to the effect that undertaking a justificatory commitment isn't sufficient for asserting quite compelling. The argument, in a nutshell, is that a speaker can explicitly undertake a justificatory commitment by way of a performative utterance (e.g., "I hereby authorize you to claim whatever follows from $\mathrm{p}$ and I undertake the responsibility of justifying $p$ ") and yet the latter doesn't by itself count as an assertion, since the judgmental force the characterizes assertion isn't present. If this is correct, as I think it is, we can't rescue Brandom's account by interpreting $\mathrm{AD} 1, \mathrm{AD} 2$, and $\mathrm{RD}$ as merely sufficient conditions. 
the paradigmatic cases are those in which adherence to the norms AD1, $\mathrm{AD} 2$, and $\mathrm{RD}$ can be attributed to speakers by scorekeepers, since what my objections question is precisely the pride of place that Brandom wants to attribute to these norms (particularly AD2 and RD). The upshot of my arguments is not that utterances such as (2) and (4a) count as assertions despite sidestepping the paradigm, but rather that the paradigm (in case there is one) should not include AD2 or RD.

\subsection{The appropriateness of justificatory challenges}

The last objection I will consider is a variant of the one discussed towards the end of subsection 2.2 above. ${ }^{26}$ The commitment to justify is, in Brandom's account, essential to assertion, but it is a conditional commitment: by making an assertion, the speaker commits herself to justify her assertion if appropriately challenged (Brandom 1994, p. 178). Brandom defines an appropriate challenge as follows: "[A] challenge that itself has, either by default or by demonstration, the status of an entitled performance" (idem). So perhaps - the objection goes_- what is going on in (4a) is not that Albert makes an assertion while disavowing the commitment to justify it, but rather that he makes it clear to Bernard that the latter is not entitled to challenge his assertion in this context. If Bernard lets Albert "get away with" 27 his assertion and with his implicit claim that a challenge from Bernard is not appropriate in this context, then Albert is entitled to his assertion or, in other words, his assertion counts as justified. But that just shows that there is great variability in how the commitment to justify is discharged and not, as I want to claim, that that commitment can simply be disavowed. ${ }^{28}$ Hence, against my main claim, the conditional commitment to justify is essential to assertion or so it is being argued.

My response is that in (4a) Albert is not claiming (not even implicitly) that Bernard is not entitled to challenge his assertion. In saying "Sorry, I won't say more," Albert can be interpreted as simply refusing to undertake a commitment to justify his assertion, and he can do so even while acknowledging that Bernard is entitled to demand a justification.

26 I also owe this objection to Mark Crimmins.

27 "[A] justification is whatever the community treats as one - whatever its members will let assertors get away with" (Brandom 1983, p. 644).

28 See Kölbel (2011, p. 66): "if I say that asserting that $p$ implies certain obligations of the asserter, then I want to allow for a good deal of variation in whether and how these obligations are enforced in different kinds of conversation". 
We can imagine a somewhat contrived continuation of their dialogue, in which Bernard asks: "So are you saying that I am in no position to ask you to justify what you just said?," and Albert replies: "No, I am not saying that. You are perfectly entitled to demand a justification for my assertion, but I am simply not going to provide one". Regardless of the improbability of this exchange, the important point illustrated by it is that the speaker's refusal to offer a justification is logically independent of his challenging the audience's entitlement to demand one. If this is correct, then a speaker can assert something while disavowing even the conditional commitment to justify her assertion if appropriately challenged.

The implausibility of trying to rescue the commitment account by insisting that the commitment to justify one's assertions, although always present, is merely conditional, is made more patent if we compare asserting with promising - as Brandom himself does, since he takes it that promising also consists in the undertaking of a task-responsibility. ${ }^{29}$ In the case of promising, the task-responsibility is to perform the promised action or to offer a suitable justification for not doing so. If in a certain context a speaker wants to avoid incurring this task-responsibility, she can hedge her utterance by saying, for instance, "I plan to be at the party, but I can't promise." Notice that, in cases like this, the speaker disavows the task-responsibility characteristic of promising by avoiding making a promise. By contrast, in (4a) the speaker disavows the task-responsibility to justify her assertion without hedging the assertion in any way. And, as I argued above, the audience (Bernard) acknowledges this by proceeding to infer (5) on the basis of the speaker's utterance (plus the appropriate background information). Thus, in light of this disanalogy with promising, it seems an ad hoc move to insist that, in cases of asserting, the task-responsibility to justify one's assertions is always present, although many times it simply does not go into effect.

\section{Assertion and trust}

So far I have been pursuing the negative goal of showing that assertions imply neither the speaker's commitment to justify the proposition asserted, nor the speaker's issuing a deferring license to her audience. If I am correct in both of these points, then the commitment account is wrong. Now I want to turn to the positive goal of the paper, that of sketching an alternative account - the trust account. Let me

${ }^{29}$ See Brandom (1994, pp. 163-5). 
emphasize that what I will offer here is merely a sketch, leaving a complete defense of my position for future work.

Recall that in section 1 I introduced Brandom's version of the commitment account as an attempt to provide an informative rendering of (CS2), the second element in the philosophical commonsense view of assertion:

(CS2) To assert that $p$ is to present the proposition that $\mathrm{p}$ as true by presenting oneself as having adequate or sufficient grounds for taking $p$ as true.

Brandom interprets the phrase "presenting oneself as having adequate or sufficient grounds for taking $p$ as true" as the undertaking of a justificatory commitment, and I have argued that this is incorrect. Now I will propose what I see as a more promising reading of this crucial component of (CS2). What is involved in presenting oneself as having adequate grounds for taking $p$ as true, if this is not a commitment to justify $p$ ? My suggestion is this: presenting oneself as having adequate grounds for taking $p$ as true involves presenting oneself as being trustworthy regarding $p$ 's truth. The invocation of trust already marks a crucial difference between my interpretation of (CS2) and Brandom's: while for Brandom presenting oneself as having adequate grounds for taking $p$ as true involves the commitment to actually justify $p$ if suitably challenged, in my view what is involved in such presentation is the speaker's presenting herself as being such that she could justify $p$, not that she would actually do so, not even after being suitably challenged (which, of course, doesn't preclude the possibility that in certain cases the speaker does engage in such justification; my point is that undertaking a justificatory commitment isn't necessary for asserting). And I claim that presenting oneself as being such that one could justify $p$ amounts to presenting oneself as being trustworthy regarding $p$ 's truth. ${ }^{30}$

As many philosophers have observed, ${ }^{31}$ when a person trusts another on a certain matter the former is (at least to a certain degree)

30 There are some important affinities between my proposed account of assertion and what is called the "assurance view" of testimonial justification. (For important presentations of the latter, see Moran 2005 and Hinchman 2005; 2014). There are also crucial differences between them, however, the more salient one being that I am proposing an account of assertion, whereas the assurance view focus, precisely, on the speech act of assurance. For an extended discussion of the differences between assertion and assurance see Lawlor (2013). I briefly discuss one of these differences below in the text.

31 See, for example, Becker (1996) and Dasgupta (1988). 
willingly refusing to undertake an active investigation to collect evidence that would show that the latter is in fact trustworthy; if the former does undertake such an investigation, this demonstrates that she does not trust the other person on the matter at hand. Conversely, when a person presents herself as trustworthy on a certain matter, she does so in the hope that she will not have to produce evidence showing that she is in fact trustworthy (which, again, doesn't preclude the possibility that in certain circumstances the person may be forced to recognize that producing such evidence is indeed appropriate). Applying this second general feature of the dynamics of trust and trustworthiness to the case of assertion, we get the result I mentioned in the previous paragraph: in asserting that $p$, a speaker presents herself as being such that she could justify $p$, not as being committed to do so in fact. ${ }^{32}$

Let me employ once more the cancellation test, this time to show that the speaker's presenting herself as trustworthy is indeed a necessary condition of assertion. Suppose that Albert had said the following to Bernard:

(9) There is a downsizing coming in a couple of weeks, but you can't trust me on that.

Now compare (9) with (4a):

(4a) Sorry, I won't say more, but there is a downsizing coming in a couple of weeks.

The relevant difference between (9) and (4a) for our purposes is that whereas Bernard is able to infer from (4a) (plus background information) that there is a downsizing coming in the Planning department in a couple of weeks, he is not similarly able to infer this from (9). The reason why not is precisely that disavowing the presumption that one is trustworthy regarding the object of one's assertion, as the speaker does in (9), immediately disqualifies one as an assertor, given that it amounts to an admission that one lacks adequate grounds for taking $p$ as true. ${ }^{33}$ Thus,

32 On the audience's side, this general feature of trust implies that one doesn't need positive evidence that the speaker is trustworthy in order to take her utterance as an assertion; however, one does need to lack conclusive evidence that she is not (see footnote 18).

33 This would make (9) similar to (7), where the speaker explicitly states that she lacks justification for her putative assertion. Both utterances cannot be counted as asserting the relevant proposition given that they violate (CS2). 
given that (9), unlike (4a), fails the cancellation test, this constitutes evidence that the speaker's presenting herself as trustworthy regarding $\mathrm{p}$ is indeed a necessary condition for asserting $p .^{34}$

Let me consider briefly one rather obvious objection to my proposal. One may object that the following utterance does seem to pass the cancellation test, despite the speaker's apparent refusal to present herself as trustworthy:

(10) It is snowing outside, but don't trust me on that, go and see for yourself.

Does (10) count as an assertion that it is snowing outside? Intuitively it does, but I do not think that this creates trouble for my account. The reason is that the speaker in (10) is not, like the speaker in (9), cancelling the presumption that she is trustworthy regarding $p$ 's truth; rather, what she is doing is simply anticipating her audience's disbelief concerning the asserted proposition, and doing so is clearly compatible with asserting something. More generally, I can present myself as trustworthy while expecting that this presentation will fall flat, and I may even make explicit this expectation and yet insist in so presenting myself. A speaker can do exactly this while asserting something, as in (10). But this does not show that the speaker's presenting herself as trustworthy is not a necessary condition of assertion; what it does show is that the audience's acceptance of such presentation is not a necessary condition for the speaker's being able to assert something. This is a plausible result, and so it is a good feature of my account that it is able to accommodate it, for otherwise the account would be collapsing the distinction between assertion and assurance.

The distinction I have in mind is this. When a speaker assures her audience that $p$, not only is the she presenting herself as trustworthy regarding $p$ 's truth but, more importantly, she is also putting forward her utterance as giving the audience a sufficient reason for believing $p$ (and the audience recognizes this). Since the utterance by itself is supposed to be a sufficient reason for believing $p$, the speaker expects her audience to forgo any further investigation concerning $p$ 's truth; in other words,

34 Notice that if I am correct that (4a) does count as an assertion of the relevant proposition despite the speaker's explicit refusal to undertake a justificatory responsibility, this shows that one can present oneself as trustworthy in asserting $p$ while explicitly refusing to justify one's assertion. And this, in turn, marks a further important difference between the trust account and the commitment account. 
the former expects the latter to form the belief that $p$ simply on the basis of trust. Thus, it can be said that assuring someone that something is the case amounts to issuing an invitation to trust. ${ }^{35}$ And the crucial feature of assurance is this: unless the audience accepts the speaker's invitation to trust her concerning $p$ 's truth, it cannot properly be said that the speech act of assurance has been consummated ${ }^{36}$ If, for example, the audience undertakes an investigation to verify whether $p$ is true and only then proceeds to form the belief that $p$, then it isn't the case that the speaker has successfully assured the audience of anything. Similarly, if the speaker recognizes in advance (as in (10)) that her audience can't or won't form the belief that $p$ simply on the strength of her word, then the speaker isn't in a position to assure her audience of anything (let alone doing it successfully). In sum, assurance is a speech act with demanding uptake conditions on the audience's side in order to be properly consummated (as in the first case), and that requires specific trust-friendly conditions in order to come into existence at all (as in the second one).

By contrast, and as I explained above, the speech act of assertion is less demanding in precisely these two aspects — even though it involves, like assurance, the speaker's presenting herself as trustworthy. First, assertion doesn't require, in order to be consummated, that the audience accepts the speaker's self-presentation as trustworthy. This means that an assertion, unlike an assurance, survives intact even when the audience refuses to take the speaker at her word and proceeds to verify whether her utterance is true. Second, assertion doesn't require, in order to come into existence, that the situation be such that it is in principle adequate for the audience to form the belief that $p$ simply on the basis of the speaker's utterance. Rather, as (10) illustrates, the speaker can very well assert that $p$ and acknowledge that the situation is such that she doesn't expect her audience to form that belief that $p$ simply on the basis of trust. This acknowledgment on the speaker's side is precisely what may lead her to undertake, as a contingent fact, a justificatory commitment of the kind Brandom mistakenly conceived as necessary for asserting something.

This concludes my sketch of the trust account. Of course, I do not take myself to have offered anything near a full defense of it; rather, my

35 This feature of assurance is thoroughly explored by Hinchman (2005), focusing on the speech act he calls "telling."

36 See Hinchman (2005, p. 567): “A[udience] consummates S[peaker]'s act [of telling] by accepting her invitation only when he regards himself as having an entitlement to believe what she told him based in trust." 
goal was simply to put forward an alternative to the commitment account's interpretation of (CS2), and to present some reasons for thinking that it is indeed a more promising one.

\section{Conclusion}

In this paper I have showed that Brandom's analysis of assertion in terms of issuing a deferring license (AD2) and undertaking justificatory responsibility $(\mathrm{RD})$ is inadequate, since the analysis suggests that these conditions are either necessary for making assertions or constitutive of paradigmatic cases of assertion. I have argued that neither is the case: first, a speaker can assert (and be taken by her audience as asserting) that $p$ while explicitly disavowing these commitments, as in examples (2) and (4a) above, and so these commitments cannot be necessary conditions of assertion. Second, Brandom cannot assume that assertions satisfying $\mathrm{AD} 2$ and $\mathrm{RD}$ constitute paradigmatic cases and that utterances such as (2) and (4a) are "bare" or parasitic assertions, since this presupposes that we already know that $\mathrm{AD} 2$ and $\mathrm{RD}$ are essential components of the paradigmatic cases, something that has been disputed by my arguments.

I also argued that, as far as a paradigm of assertion can be discerned, it includes at least conditions (CS1) and (CS2). My cancellation test revealed that these conditions are indeed necessary for assertion (see, respectively, (1) and (7)) because, unlike Brandom's AD2 and RD, they cannot be cancelled while asserting that $p$. Finally, I sketched an alternative to Brandom's commitment account, namely, the trust account, and provided some reasons for thinking that it offers a more promising interpretation of (CS2). However, it remains a task for future work to provide a more complete defense of this alternative.

\section{References}

Austin, J. L. (1975), How to Do Things with Words, Cambridge, Harvard University Press.

Bach, K. y Harnish, R. M. (1979), Linguistic Communication and Speech Acts, Cambridge, The MIT Press.

Becker, L. C. (1996), "Trust as Noncognitive Security about Motives," Ethics, 107, pp. 43-61.

Brandom, R. (1983), "Asserting," Nous, 17, pp. 637-650.

Brandom, R. (1994), Making it Explicit, Cambridge, Harvard University Press. 
Brandom, R. (2010), "Conceptual Content and Discursive Practice," Grazer Philosophische Studien, 81, pp. 13-35.

Brown, J. and Cappelen, H. (eds.) (2011), Assertion, Oxford, Oxford University Press.

Dasgupta, P. (1988), "Trust as a Commodity," in Gambetta, D. (ed.) Trust: Making and Breaking Cooperative Relations, New York, Basil Blackwell, pp. 49-72.

Dummett, M. (1959), "Truth", Proceedings of the Aristotelian Society, 59, pp. 141-162.

Hinchman, E. (2005), "Telling as Inviting to Trust", Philosophy and Phenomenological Research, 70, pp. 562-587.

Hinchman, E. (2013), "Assertion, Sincerity and Knowledge," Nous, 47, pp. 613-646.

Hinchman, E. (2014), “Assurance and Warrant”, Philosophers' Imprint, 14, pp. 1-58.

Kölbel, M. (2011), "Conversational Score, Assertion and Testimony", in Brown, J. and Cappelen, H. (eds.) (2011), pp. 49-78.

Lackey, J. (2008), Learning from Words, Oxford, Oxford University Press.

Lawlor, K. (2013), Assurance: an Austinian View of Knowledge and Knowledge Claims, Oxford, Oxford University Press.

MacFarlane, J. (2005), "Making Sense of Relative Truth", Proceedings of the Aristotelian Society, 105, pp. 305-323.

MacFarlane, J. (2011), "What is Assertion?", in Brown, J. and Cappelen, H. (eds.) (2011), pp. 79-96.

Moran, R. (2005), "Getting Told and Being Believed", Philosophers' Imprint, 5, pp. 1-29.

Stalnaker, R. (1978), “Assertion”, Syntax and Semantics, 9, pp. 315-322.

Stalnaker, R. (2002), "Common Ground”, Linguistics and Philosophy, 25, pp. 701-721.

Pagin, P. (2004), "Is Assertion Social?", Journal of Pragmatics, 36, pp. 833-859.

Watson, G. (2004), "Asserting and Promising”, Philosophical Studies, 117, pp. 57-77.

Williamson, T. (2000), Knowledge and Its Limits, Oxford, Oxford University Press.

Recibido el 10 de junio de 2015; aceptado el 3 de septiembre de 2015. 